\title{
Fabrication of $\mathrm{CaO}$ Insulator Coatings by MOCVD for Application in Fusion Reactor Blankets*
}

\author{
Z. Zeng and K. Natesan
}

Energy Technology Division

Argonne National Laboratory

Argonne, IL 60439

November 2001

Distribution

R. B. Poeppel

W. J. Shack

K. Natesan

Z. Zeng

S. Hagamann

For proceeding of 2001 MRS meeting, Boston, November 26-30,2001

*Work supported by U.S. Department of Energy, Office of Fusion Science, under Contract W-31-109-Eng-38. 


\title{
Fabrication of $\mathrm{CaO}$ Insulator Coatings by MOCVD for Application in Fusion Reactor Blankets
}

\author{
Z. Zeng and K. Natesan
}

Argonne National Laboratory, Energy Technology Division, Argonne, IL 60439

\begin{abstract}
The liquid lithium blanket for fusion reactors requires an electrically insulating coating on the duct to minimize the magnetohydrodynamic pressure drop that occurs during the flow of liquid metal in a magnetic field. Calcium oxide $(\mathrm{CaO})$ is a good candidate for the coating material because it is an excellent electrical insulator and it is stable in a liquid lithium environment. In this paper, details are presented on metalorganic chemical-vapor deposition method that was used to fabricate the $\mathrm{CaO}$ coating. Composition and phase analyses of the coating were performed by energy dispersive X-ray analysis and X-ray diffraction. Scanning electron microscopy images show that the coating did not crack after several thermal cycles from room temperature to $715^{\circ} \mathrm{C}$. The resistance of the coating is high enough for an insulating coating on the liquid lithium blanket of fusion reactors.
\end{abstract}

\section{INTRODUCTION}

In fusion reactor designs, liquid metals are used as a coolant in fusion reactor blankets. The main challenge in the design of self-cooled blankets is to accommodate the strong influence of the magnetic field on the liquid-metal flow. The magnetic field can cause a large electrical current if the duct wall is a conductor. An electrical current flowing perpendicular to a magnetic field results in a mechanical force that leads to a magnetohydrodanamic (MHD) pressure drop. This pressure drop could be as high as $8.6 \mathrm{MPa}$ in a poloidal duct of an inboard blanket segment [1]. Therefore, insulator coatings on the duct wall are needed to reduce the MHD pressure drop.

Lithium-containing liquid metals are attractive materials in fusion reactor blankets. The insulator coatings should be compatible with liquid lithium, which is a very strong reduce reagent. $\mathrm{CaO}$ is a good candidate as a coating material since it is a good insulator and its free energy $\left(-128 \mathrm{kcal} / \mathrm{mol}\right.$ at $\left.700^{\circ} \mathrm{C}\right)$ is lower than that of $\mathrm{Li}_{2} \mathrm{O}\left(-114 \mathrm{kcal} / \mathrm{mol}\right.$ at $\left.700^{\circ} \mathrm{C}\right)$. Experiments show that $\mathrm{CaO}$ is stable in liquid lithium [2,3].

Metalloragnic chemical vapor deposition (MOCVD) provides a promisingmethod to prepare a $\mathrm{CaO}$ coating on a complex channel geometry for the fusion reactor blanket. In this paper, we report the preparation of $\mathrm{CaO}$ coatings by the MOCVD method.

\section{EXPERIMENTAL}

The $\mathrm{CaO}$ coatings were fabricated in a low pressure, cold wall MOCVD system. The MOCVD apparatus used in this study is shown in Fig. 1. Calcium bis(2,2,6,6-tetramethyl-3,5heptanedionato) $\left[\mathrm{Ca}(\mathrm{TMHD})_{2}\right]$ is used as a precursor for the $\mathrm{CaO}$ coating. The vapor pressure of this chemical is low. To achieve a precursor pressure high enough for the MOCVD coating, the chemical has to be heated over $200^{\circ} \mathrm{C}$. However, this precursor starts to decompose at $240^{\circ} \mathrm{C}$. 


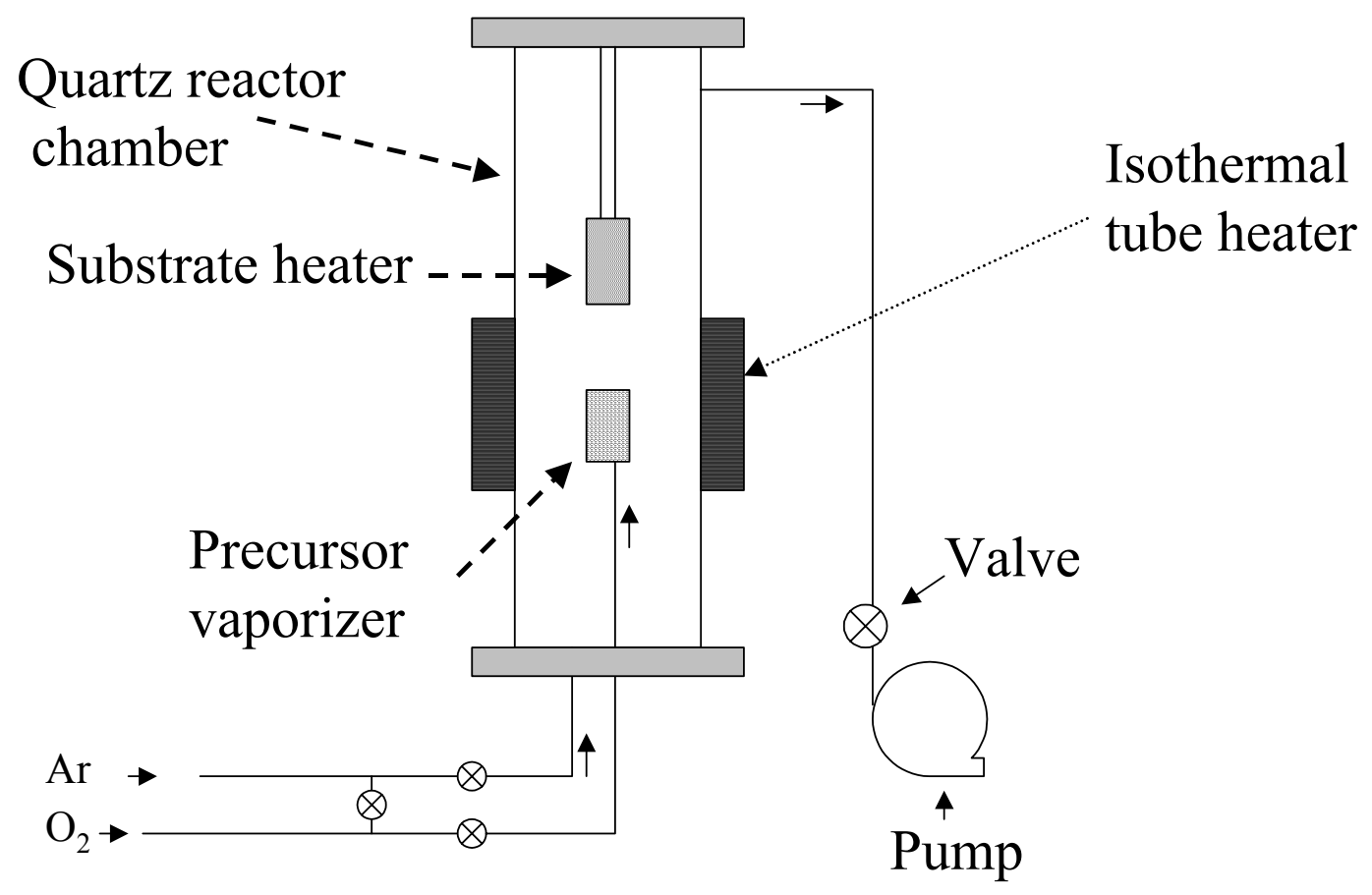

Figure 1. Schematic diagram of MOCVD apparatus for $\mathrm{CaO}$ coating

Since the temperature window is so narrow, the vaporizer has to be assembled in the quartz reactor, so that the distance between the vaporizer and the sample heater is kept as short as possible. In that way, the temperature can be easily controlled to avoid the precursor condensing or decomposing.

V-4Cr-4Ti specimens $(2 \times 1 \times 0.2 \mathrm{~cm})$ were heated to $650^{\circ} \mathrm{C}$. Ca precursor was carried out with $99.999 \% \mathrm{Ar}$ and a flow rate of $40 \mathrm{sccm}$ (standard cubic centimeters per minute). The oxygen flow rate was $760 \mathrm{sccm}$. The pressure in the chamber was 1.7 torr. Specimens were cooled to room temperature at a controlled rate of $5^{\circ} \mathrm{C} / \mathrm{min}$ in an oxygen flow.

Scanning electron microscopy (SEM) and energy dispersive X-ray (EDX) analysis were performed with a JSM-6400 scanning electron microscope. Resistances were measured by a two-probe method in an Ar gas flow from room temperature to $715^{\circ} \mathrm{C}$.

\section{RESULTS}

\section{Effect of vaporizer temperature on the sublimation rate of precursor and the growth rate of $\mathrm{CaO}$ coatings}

The vaporizer in our MOCVD equipment is removable. Therefore, the mass of the sublimated precursor could be acquired by measuring the mass loss of the vaporizer. The sublimation rate of the $\mathrm{Ca}(\mathrm{TMHD})_{2}$ precursor at $225^{\circ} \mathrm{C}$ is much higher than that at $205^{\circ} \mathrm{C}$ (Fig. 2). The partial pressure of the precursor should increase with higher vaporizer temperature, which would lead to a higher $\mathrm{CaO}$-coating growth rate (Fig. 3). 


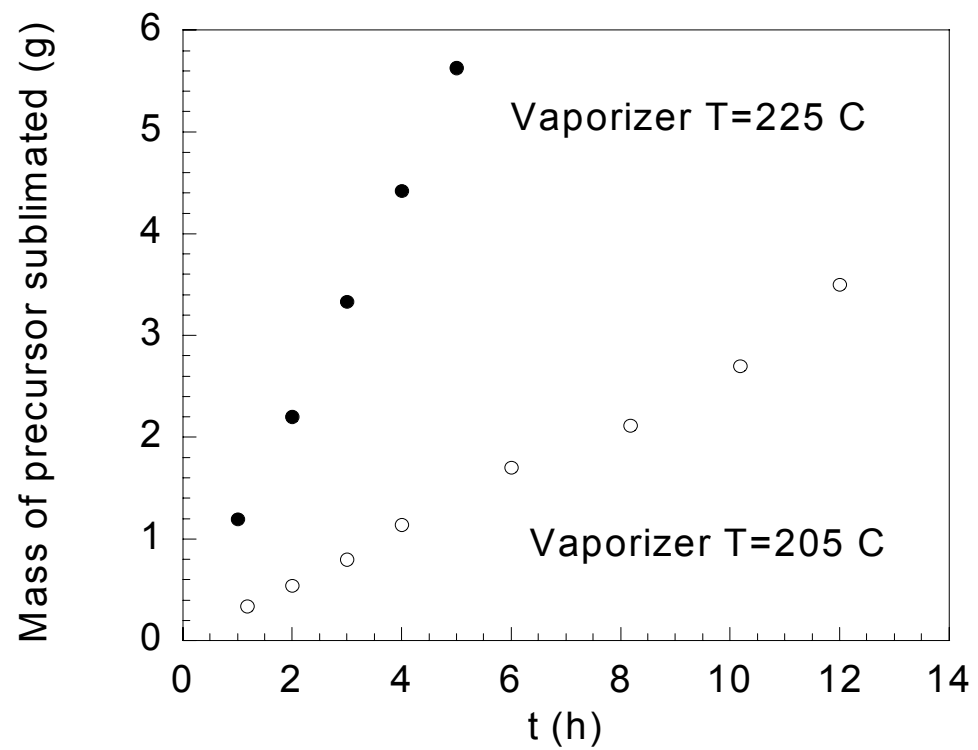

Figure 2. $\mathrm{Ca}(\mathrm{TMHD})_{2}$ precursor sublimation rate for Ar carrier gas with flow rate of 40 $\mathrm{sccm} / \mathrm{min}$ and pressure of 1.6 torr.

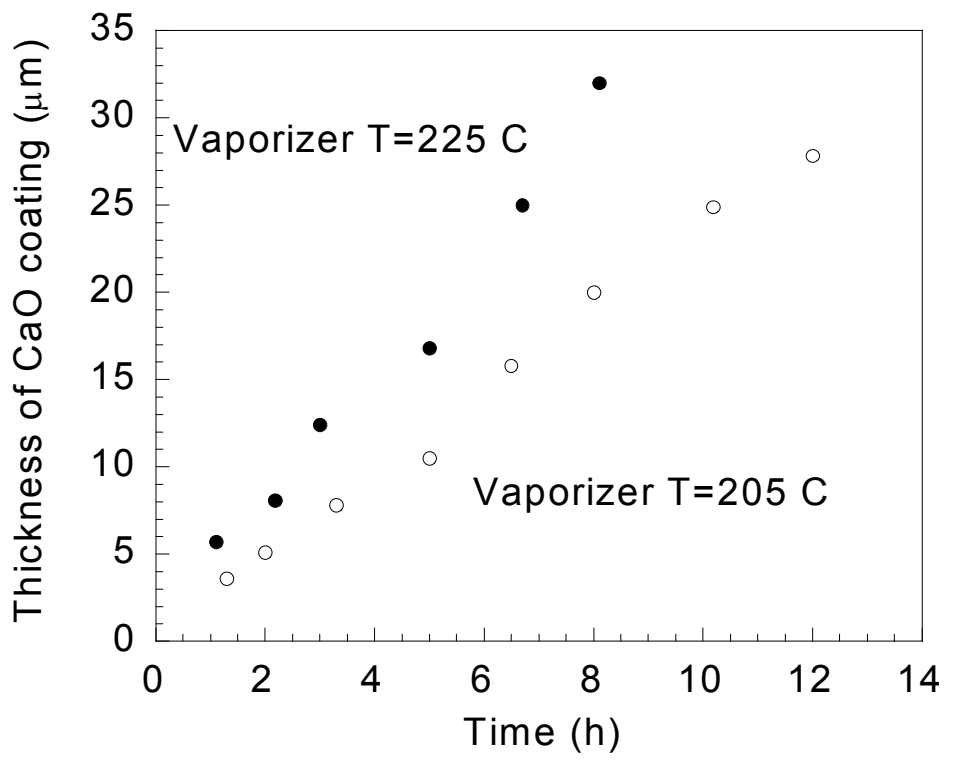

Figure 3. $\mathrm{CaO}$ coating growth rate for Ar carrier gas with flow rate of $40 \mathrm{sccm} / \mathrm{min}$ and pressure 1.6 torr. 


\section{Effect of substrate temperature on $\mathrm{CaO}$ coatings}

When the substrate temperature is $750^{\circ} \mathrm{C}$, vanadium alloy is easily oxidized. A vanadium oxide layer was observed between the vanadium alloy and $\mathrm{CaO}$ coating. In the liquid lithium environment, vanadium oxide can be reduced by $\mathrm{Li}$, which causes the $\mathrm{CaO}$ coating to split. $\mathrm{A}$ $\mathrm{CaCO}_{3}$ impurity formed when the substrate temperature was $550^{\circ} \mathrm{C}$. Therefore, $650^{\circ} \mathrm{C}$ is a good temperature for forming a $\mathrm{CaO}$ coating on the substrate of vanadium alloy.

Figure 4 shows a SEM photomicrograph of $\mathrm{CaO}$ coated $\mathrm{V}$-alloy specimens. The $\mathrm{CaO}$ layer was fairly compact and uniform. No crack was found after 5 thermal cycles from 25 to $715^{\circ} \mathrm{C}$. Therefore, thermal expansion did not cause a problem for the $\mathrm{CaO}$ coating fabricated by MOCVD. EDX analysis showed almost no vanadium in the $\mathrm{CaO}$ coating layer (Fig. 5). This condition is desirable since some vanadium oxides such as $\mathrm{V}_{2} \mathrm{O}_{4}$ are good conductors and decrease the resistance of the coating if they are in the $\mathrm{CaO}$ layer.

The major phase in X-ray the diffraction pattern is $\mathrm{CaO}$ (Fig. 6). Sharp diffraction peaks indicate a well crystalline coating. The SEM image (Fig. 4) also shows the cubic shape of the particles, with average grain size $\sim 2 \mu \mathrm{m}$. No vanadium oxide was detected by X-ray diffraction. EDX analysis also indicated no vanadium in the film. Therefore, the coating is pure $\mathrm{CaO}$.
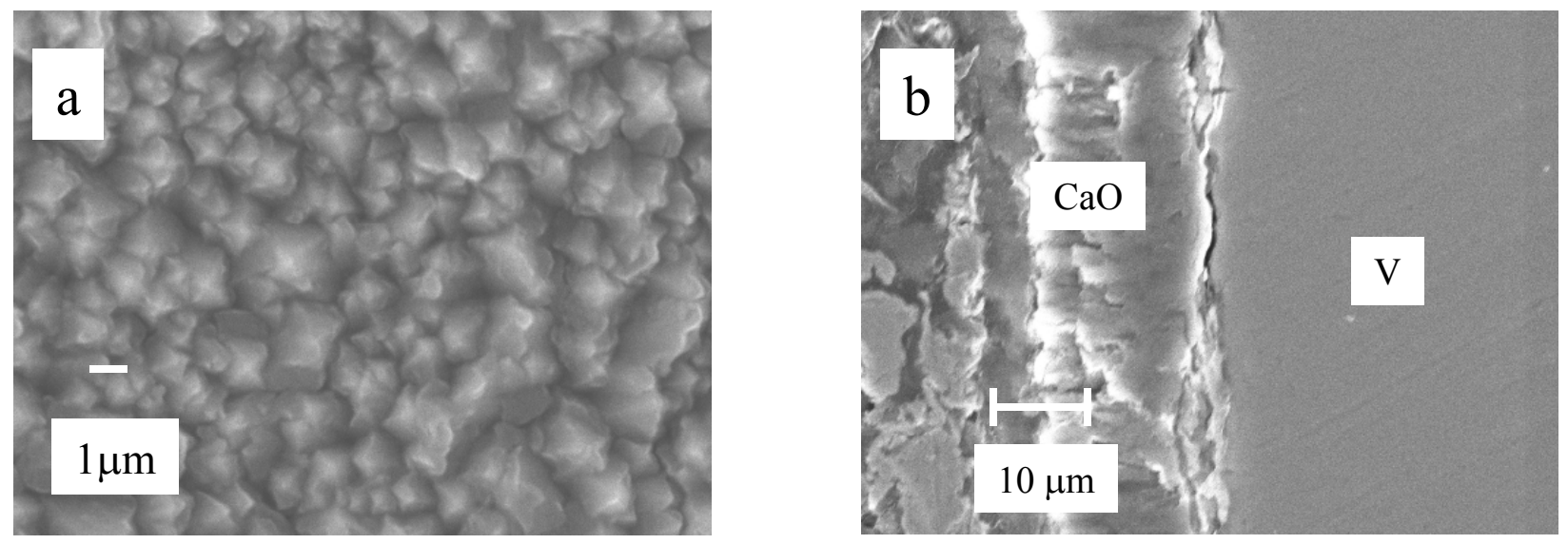

Figure 4. SEM photomicrograph of $\mathrm{CaO}$ coated V-alloy specimens (a) surface image, (b) cross section

The resistance of the coating is too high to measure at room temperature. The minimum value of the product of resistance and the coating area (RxA) is $100 \Omega \bullet \mathrm{cm}^{2}$ to obtain an acceptable pressure drop for the fusion blanket. The RxA for a $20-\mu \mathrm{m} \mathrm{CaO}$ coating forming by MOCVD is $2 \times 10^{7} \Omega \bullet \mathrm{cm}^{2}$ at $715^{\circ} \mathrm{C}$. This value is much higher than the requirement. Figure 7 shows RxA increases with decreasing temperature from 720 to $450^{\circ} \mathrm{C}$. 


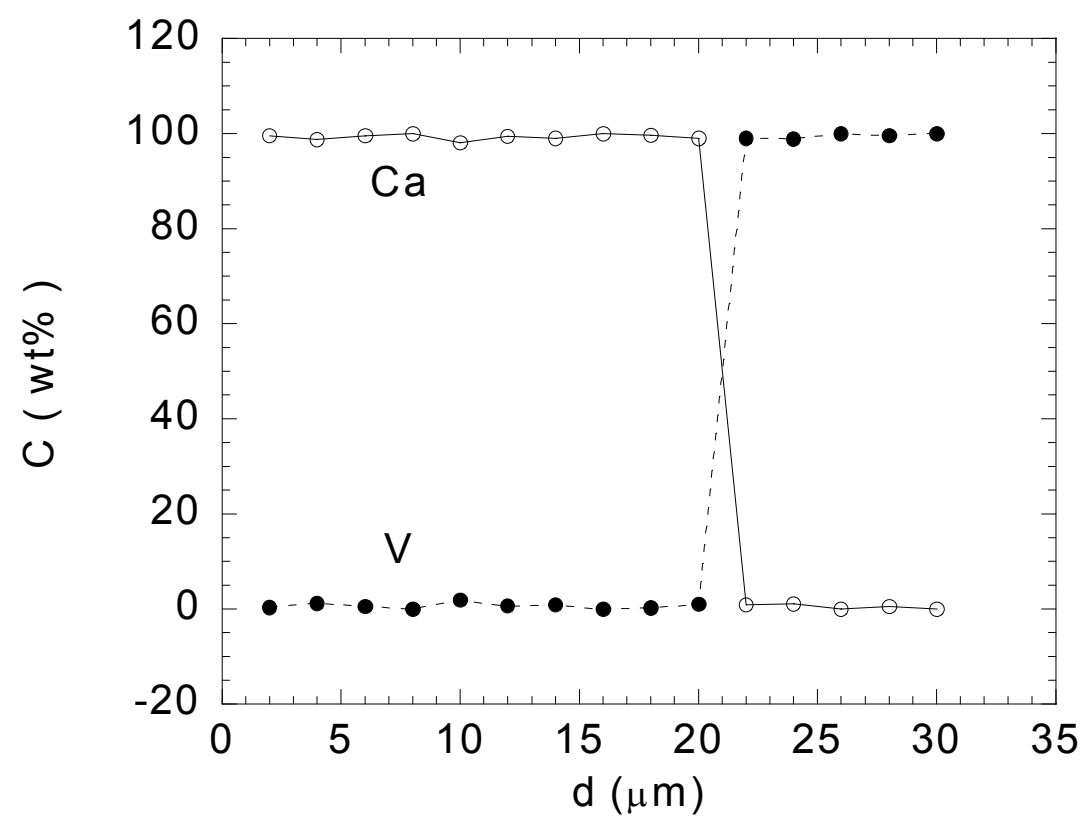

Figure 5. $\mathrm{EDX}$ depth profiles for $\mathrm{Ca}$ and $\mathrm{V}$ of $\mathrm{CaO}$ coating

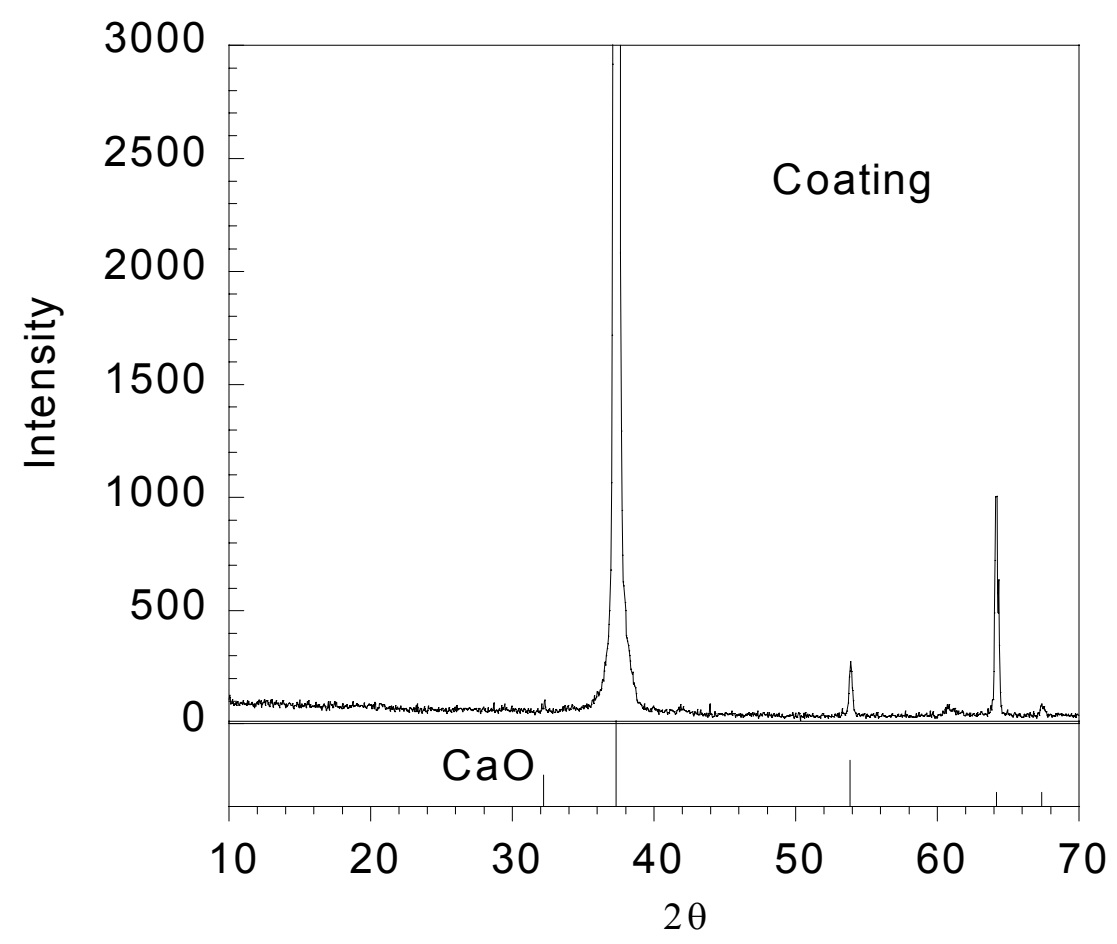

Figure 6. X-ray diffraction of $\mathrm{CaO}$ coating 


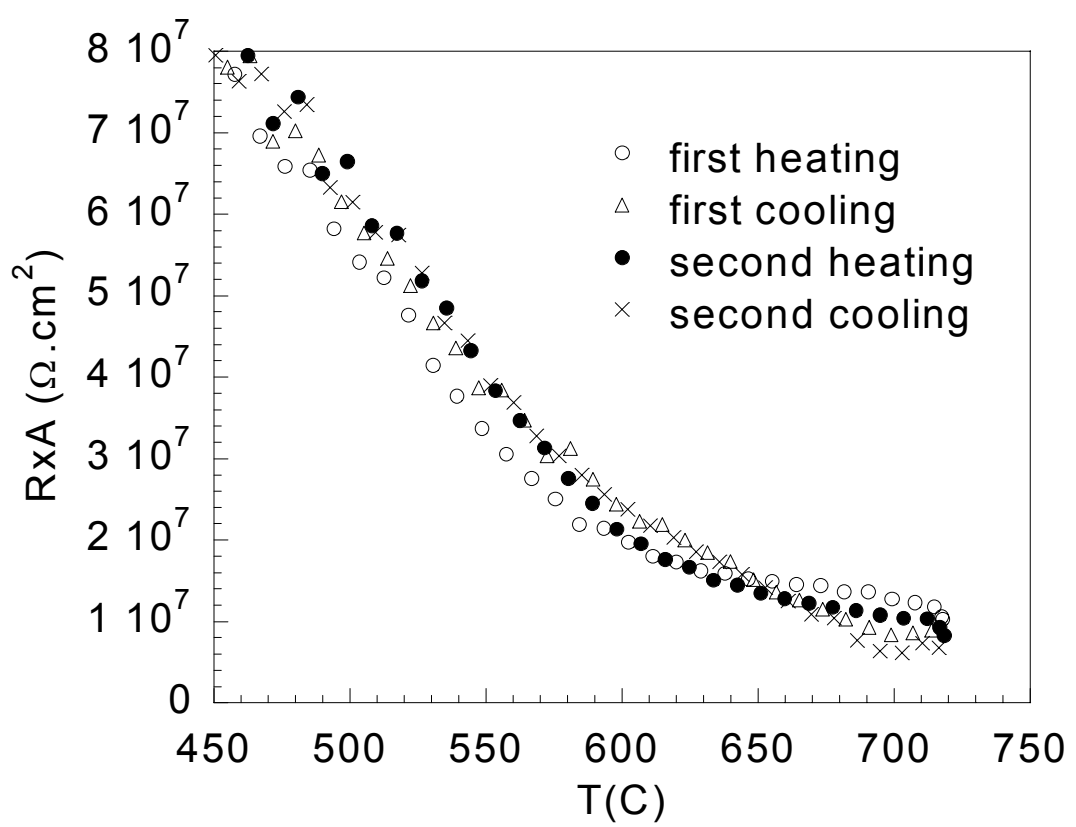

Figure 7. Product of resistance and area as a function of temperature

\section{CONCLUSIONS}

$\mathrm{CaO}$ coatings as thick as $40 \mu \mathrm{m}$ on vanadium alloy are prepared by MOCVD. This provides a possibility to coat $\mathrm{CaO}$ on a complex channel geometry for the fusion reactor blanket. $\mathrm{X}$-ray diffraction shows the coatings to be pure $\mathrm{CaO}$. No vanadium impurity was found in the $\mathrm{CaO}$ layer from EDX analysis. The $\mathrm{CaO}$ layers were fairly compact. No crack was found after 5 thermal cycles from 25 to $715^{\circ} \mathrm{C}$. Resistances of the coatings were high enough for the insulator application to reduce the MHD pressure for a fusion reactor.

\section{ACKNOWLEDGEMENTS}

The author thanks W. E. Ruther and D. Rink for assistance in development of MOCVD equipment. Work supported by U.S. Department of Energy, Office of Fusion Science, under Contract W-31-109-Eng-38.

\section{REFERENCES}

1. S. Malang and L. Buhler, Argonne National Laboratory Report ANL/FPP/TM-269 (Aug. 1994)

2. J.-H. Park, T. Domenico, G. Dragel, and R. Clark, Fusion Engineering and Design 27, 682 (1995)

3. K. Natesan, C. B. Reed, M. Uz, J. H. Park, and D. L. Smith, Argonne National Laboratory Report ANL/TD/TM00-10 (May 2000) 